\title{
Effect of residual stress on recrystallization behavior of mechanically
}

\section{alloyed steels}

\author{
I. Toda-Caraballo ${ }^{1}$, Chao $^{1}$, L.E. Lindgren ${ }^{2}$ and C. Capdevila ${ }^{1}$ \\ ${ }^{1}$ Materalia Research Group, Department of Physical Metallurgy, Centro Nacional de \\ Investigaciones Metalúrgicas (CENIM-CSIC), Avda. Gregorio del Amo, 8. E-28040 \\ Madrid, Spain \\ ${ }^{2}$ Division of Computer Aided Design, Luleå University of Technology, S-97187 Luleå, \\ Sweden
}

\begin{abstract}
This paper presents a finite element modeling analysis of deformation on iron-base mechanically alloyed oxide dispersion strengthened alloy by spherical indentations (Brinell test). Results of the model are used to interpret the role of residual shear stresses on the development of recrystallized grain structure and the temperature at which recrystallization occurs.
\end{abstract}

Keywords: finite element analysis; recrystallization; mechanical alloying; oxide dispersion strengthened alloy; residual stresses.

Mechanical alloying is a process in which mixtures of powders are severely deformed until they form atomic solutions. Inert oxides can also be introduced to form a 
dispersion of fine particles which strengthen the consolidated product. Significant quantities of iron and nickel-base alloys, with unusual properties, are produced commercially using this process. The total true strain during mechanical alloying can be as large as 9, and there are evidences that this leads to mixing on an atomic scale and to the development of a uniform grain structure which is sub-micrometer in size [1-3]. Following mechanical alloying, the particles are consolidated using standard powder metallurgical techniques. The consolidated metal has a very large stored energy, approaching $1 \mathrm{~J} \mathrm{~g}^{-1}$ [4]. This ought to make it easy to induce recrystallization, but in practice the alloys fail to recrystallize except at very high temperatures close to melting [2]. On the other hand, the recrystallization temperature can be reduced dramatically by slightly deforming the consolidated product prior to heat treatment [5]. It is in this context that the effect of deformation on PM 2000 by spherical indentations (Brinell test) on the development of recrystallized grain structure is studied here.

The Fe-base oxide dispersion strengthened PM 2000 (Fe-20Cr-6Al-0.5Ti-0.5 $\mathrm{Y}_{2} \mathrm{O}_{3}$ ), supplied by PLANSEE GmbH, is created by mechanical alloying. The powders with a grain size of about $70 \mathrm{~nm}$ were therefore consolidated by hot isostatic pressing and subsequently by hot rolling of vacuum - sealed cans at about $1000{ }^{\circ} \mathrm{C}$ to form a $7 \mathrm{~mm}$ wall-thickness tube. During this stage dynamic recovery and recrystallization occur to produce a mixture of elongated deformed grains and relatively equiaxed recrystallized grains with a sub-micrometric grain size in the transverse direction and a strong $<110>$ fibre texture [6-7]. Prismatic samples of $60 \mathrm{~mm}$ in length and $20 \times 7 \mathrm{~mm}^{2}$ section have been machined from the tube in as-received condition to perform spherical indentations at the inner wall. A $10 \mathrm{~mm}$ in diameter spherical indenter has been used. Loads ranging from 4.9 to $49 \mathrm{kN}$ have been applied. Hereafter, the Brinell tested material is referred as deformed material. 
A systematic study of the early stages of recrystallization as a function of annealing

Table 1. $T_{R}$ values vs. Brinell load after three hours isochronal heat treatments

\begin{tabular}{cc}
\hline Brinell test loads $(\mathrm{kN})$ & $\mathrm{T}_{\mathrm{R}}\left({ }^{\circ} \mathrm{C}\right)$ \\
\hline 49.0 & 1150 \\
29.4 & 1210 \\
19.6 & 1250 \\
4.9 & 1320 \\
0 & 1330 \\
\hline
\end{tabular}

Optical microscopy analysis on non- recrystallized samples reveled that a very elongated and coarse-grained microstructure, characteristic of a secondary recrystallization process in ferritic ODS alloys [8-11], is developed. Regarding deformed samples, it was observed that the lower the deformation, the bigger the grain size and fewer the number of recrystallized grains that appear in the microstructure. In the area affected by deformation, the recrystallized grain is equiaxed in the early stages, but following growth in the parallel direction to the surface produces elongated grains which finally coarsen in the normal direction to the surface. Figure 1 illustrates the 
effect of increasing deformations on subsequent recrystallization of PM 2000. It is evident the effect of the deformation magnitude on the recrystallization, since the bigger the indentation load, the more extended the volume of recrystallized material and finer the recrystallized grain size.

These results are consistent with the ones reported by Nutting [8] and Capdevila et al [1]. Nutting studied the recrystallization process in a $60 \%$ cold worked sheet which was slightly deformed by bending, and claimed that recrystallization was triggered in places subjected to residual compressive stresses [8]. Capdevila reported a two fold effect on the recrystallization behavior of specimens subjected to different bending angles: As cold deformation increases it was noted a decrease in the recrystallization temperature and an increase in the density of recrystallization nuclei disregarding of the stress direction [1].

Recrystallization requires volumetric free energy terms of stored energy of dislocations to drive the migration of the boundaries around the growing grains. When the material is under stress there are additional terms and it is these which we will concentrate on here. It was noted that both the velocity and the direction of migration of high angle boundaries varied, depending on their misorientation [12]. It is possible to interpret these results in terms of applied stress acted to drive the movement of structural dislocations in the boundary [13]. It was also noted that the migration mechanism of grain boundary motion is different in a stressed material than the mechanism of curvature driven grain boundary motion (or texture induced) in a non-stressed material [13-15]. During indentation the material flow occurs in the extrusion direction, so it is assumed that no texture change takes place. These facts and the grains morphology due to extrusion process suggest the special importance to the shear stress component of the beginning of recrystallization. 
In order to discern the effect of the residual stress on the recrystallization a Finite MSC.Marc provided by Luleå University of Technology. The results were analyzed comparing the aspect of the recrystallized zones with those of the iso-strain and $\sigma_{x y}$ isostress contours. Although Von Mises stress is related to dislocation glide, the glide related to parallel to grain boundaries are more important. Von Mises stress is isotropic and will miss the influence of the larger amount of grain boundaries parallel with the $\mathrm{x}$ axis. As it was described above, the material flow is not isotropic, but occurring in extrusion direction. For this reason the stress analysis described below is focused on the $\sigma_{x y}$ shear stress component distribution instead of Von Mises stress distribution, which its isotropic character will miss the anisotropy of the grain boundary movement.

The simulations were performed considering a spherical steel ball of $5 \mathrm{~mm}$ in radius as indenter with isotropic linear elastic behavior. The contact between spherical indenter and sample was modeled as Coulomb friction with a friction coefficient of 0.1 . The loads considered in calculations were ranging from 4.9 to $49 \mathrm{kN}$. Simulations were performed on a $7 \mathrm{~mm}$ in thickness and $30 \mathrm{~mm}$ in length sample considering a mesh with cylindrical symmetry (axial symmetry around the centre of the indenter in the vertical direction). The sample was modelled as an elastoplastic material with isotropic Von Mises yield criterion and with isotropic work hardening in which the Young's modulus was $210 \mathrm{GPa}$ and the Poisson's ratio was 0.3 . The flow stress curve defined by the expression

$$
\sigma=1000+865.7 \bar{\varepsilon}_{\mathrm{p}}^{0.505}
$$

was obtained by fitting to experimental data. In this expression $\sigma$ is the true flow stress (in $\mathrm{MPa}$ ) and $\bar{\varepsilon}_{p}$ is the true plastic strain. The model accounts for large deformations 
and strains using an updated Lagrangian formulation and a finite strain model derived from the incremental theory of plasticity.

Of particular interest is the state of deformation at the temperature when recrystallization is triggered for a given load. At this state the residual stress at the unloaded state are allowed to move and relax. For this reason, the residual stress evolution (function of the initial unloaded state and temperature) during recrystallization heat treatment, has been analyzed using the finite element method and the constitutive equation proposed by Johnson - Cook [16]. In this sense, the evolution with temperature of equation (1) could be expressed as follows:

$$
\sigma=\left(\mathrm{A}+\mathrm{B} \bar{\varepsilon}_{\mathrm{p}}^{\mathrm{n}}\right)\left(1+\mathrm{C} \ln \frac{\bar{\varepsilon}_{\mathrm{p}}}{\bar{\varepsilon}_{0}}\right)\left(1-\left(\frac{\mathrm{T}-\mathrm{T}_{\mathrm{r}}}{\mathrm{T}_{\mathrm{m}}-\mathrm{T}_{\mathrm{r}}}\right)^{\mathrm{m}}\right)
$$

The parameters $A, B$, and $n$ are those defining the stress-strain curve at (1), $\mathrm{C}$ is the strain-rate coefficient considered as $1.5 \times 10^{-2}$ [17], $\dot{\varepsilon}_{0}$ is the initial plastic strain rate with a reference value of $10^{-4} \mathrm{~s}^{-1}$ and $\bar{\varepsilon}_{\mathrm{p}}$ is the plastic strain rate. The effect of the temperature is defined through $\mathrm{T}$ (current temperature), $\mathrm{T}_{\mathrm{r}}$ (room temperature, i.e. 25 $\left.{ }^{\circ} \mathrm{C}\right), \mathrm{T}_{\mathrm{m}}$ (melting temperature, i.e. $1487^{\circ} \mathrm{C}$ ) and the thermal softening constant $(\mathrm{m})$ considered as 0.6 [18]. Moreover, it was checked the negligible effect of Young's modulus temperature dependence on calculations.

Figure 2 shows a comparison between a shear residual stress $\left(\sigma_{\mathrm{xy}}\right)$ map and the early stages of recrystallization in a deformed and subsequently heat treated at $1150{ }^{\circ} \mathrm{C} / 3 \mathrm{~h}$ sample. It is clearly observed in this figure that the recrystallized zones (Fig. 2(b)) match with those where $\sigma_{x y}$ presents the highest values. This illustrates the role of shear stresses on recrystallization of Fe-base mechanically alloyed steels. However, it is clear 
from Fig. 1 that the nucleated grain tends to grow towards the area affected by indentation but not the surrounding unaffected area. Thus, residual shear stress trigger the nucleation of recrystallization and the recrystallized grains grow in the higher deformed material, which is consistent with the total strain energy map showed in Fig. 2(c).

Figure 3 shows the evolution of the ratio between $\sigma_{\mathrm{xy}}$ and $\tau_{0}$ (shear yield strength), i.e. $\delta$ $=\sigma_{\mathrm{xy}} / \tau_{0}$, with temperature. The shear stress values considered corresponds to the zone where start of recrystallization has been detected. Therefore, once $\delta$ reaches the value of one, the residual shear stress would be high enough to drive the dislocation movement, and hence to induce the movement of grain boundaries, which burst the recrystallization process. This is consistent with the idea described by Hutchinson and Wynne [18] where it is described that boundary movement is accompanied by shearing of the volume through which a boundary moves. While any high angle boundary may be formally described by a dislocation arrangement, it is not so evident which dislocations are actually involved, and how to resolve the stress that drives them. In this case, it may be easier to think of structural units and coordinated jumps of atoms across the boundary providing the mechanism for migration. Which ever view point is adopted, it is important to remember that energy has to be supplied to provide that which is being dissipated during the boundary migration. This can only come from work done by the component of force acting parallel to the boundary and so shearing must always accompany migration when this is stress-driven, whatever the misorientation of the boundary. Since each element of grain boundary is an invariant plane, the only possible work is by translation parallel to the boundary or, in other words, by shearing the volume as the boundary passes through it. In this case, the significant stress component will be a shear stress parallel to the boundary. The maximum possible driving force in 
this case is then equal to the work done per unit volume $\gamma \sigma_{\mathrm{xz}}$ where $\gamma$ is the shear strain accomplished, which depend on the misorientation and structure of the boundary.

Figure 4 shows a correlation between the corresponding temperatures at which $\delta$ becomes one, and the recrystallization temperatures listed in Table 1. The good agreement between both values allows us to conclude that shear stresses could be a parameter controlling the nucleation of recrystallisation in mechanically alloyed steels. In summary, the presence of residual shear stresses at the moment of recrystallization boosts the grain boundary movement and hence reduces the recrystallization temperature. The quantification of the parameter that governs the recrystallization in PM2000 ODS steel has been fixed when the ratio $\delta$ reaches the value of one.

\section{Acknowledgements}

I. Toda Caraballo acknowledges the Spanish Ministerio de Ciencia e Inovación for financial support in the form of $\mathrm{PhD}$ research grant (FPI). The authors acknowledge financial support for this investigation from the Spanish Ministerio de Educación y Ciencia through the Plan Nacional 2006 ENE2006-15170-C02-01/ALT.

\section{References}

[1] C. C. Montes and H.K.D.H. Bhadeshia, Adv. Eng. Mater. 5 (2003) 232.

[2] C. Capdevila and H.K.D.H. Bhadeshia, Adv. Eng. Mater. 3 (2001) 647.

[3] C. Capdevila, U. Miller, H. Jelenak and H.K.D.H. Bhadeshia, Mater. Sci. Eng. A $316(2001) 161$.

[4] T. S. Chou and H. Bhadeshia, Mater. Sci. Eng. A 189 (1994) 229.

[5] H. Regle and A. Alamo, J. Phys. IV 3 (1993) 727-731. 
[6] C. Capdevila, Y. L. Chen, N. C. K. Lassen, A. R. Jones and H.K.D.H. Bhadeshia, Mater. Sci. Technol. 17 (2001) 693.

[7] C. Capdevila, Y. L. Chen, A. R. Jones and H.K.D.H. Bhadeshia, ISIJ Int. 43 (2003) 777.

[8] J. Nutting, S. Ubhi, T.A. Hughes. Proc. Int. Conf. on Oxide Dispersion Strengthened Superalloys by Mechanical Alloying, J.S. Benjamin (Ed), IncoMAP, $198133-41$.

[9] C. Capdevila, Metall. Mater. Trans. A 36A (2005) 1547.

[10] C. Capdevila, J. P. Ferrer, F. G. Caballero and C. Garcia de Andres, Metall. Mater. Trans. A 37A (2006) 2059.

[11] J. L. Gonzalez-Carrasco, J. Chao, C. Capdevila, J. A. Jimenez, V. Amigo and M. D. Salvador, Mater. Sci. Eng. A 471 (2007) 120.

[12] C.H. Li, E.H. Edwards, J. Washburn and E.R. Parker, Acta Metall. 1 (1953) 223.

[13] M. Winning, G. Gottstein and L.S. Shvindlermann, Acta Mater. 49 (2001) 211.

[14] M. Winning, Acta Mater. 51 (2003) 6465.

[15] M. Winning, G. Gottstein and L.S. Shvindlerman, Acta Mater. 50 (2002) 353.

[16] G.R. Johnson, W.H. Cook, Proc. $7^{\text {th }}$ Int. Symp. on Ballistic. Publ. The Hague, The Netherlands. 1983 541-547

[17] H. Chang and I. Baker, Metall. Mater. Trans. A 38A (2007) 2815.

[18] B. Hutchinson and B. Wynne, Mater. Sci. Forum 550 (2007) 149. 


\section{Figure Captions}

Figure 1: Recrystallized microstructure of deformed area after annealing at $1350{ }^{\circ} \mathrm{C}$ for $3 \mathrm{~h}$ : (a) $4.9 \mathrm{kN}$ and (b) $49 \mathrm{kN}$. Transverse section to extrusion direction.

Figure 2: (a) $\sigma_{x y}$ map at $1150{ }^{\circ} \mathrm{C}$ after deformation for $49 \mathrm{kN}$ load, (b) recrystallization microstructure after $49 \mathrm{kN}$ load and subsequent annealing at $1150{ }^{\circ} \mathrm{C}$ for $3 \mathrm{~h}$, and (c) strain energy density map for $49 \mathrm{kN}$ indentation load.

Figure 3: Evolution of $\delta$ with temperature

Figure 4: Correlation between experimental $T_{\mathrm{R}}$ and temperatures at which $\delta=1\left(\mathrm{~T}_{\delta}\right)$. 
Click here to download high resolution image

\section{a)}

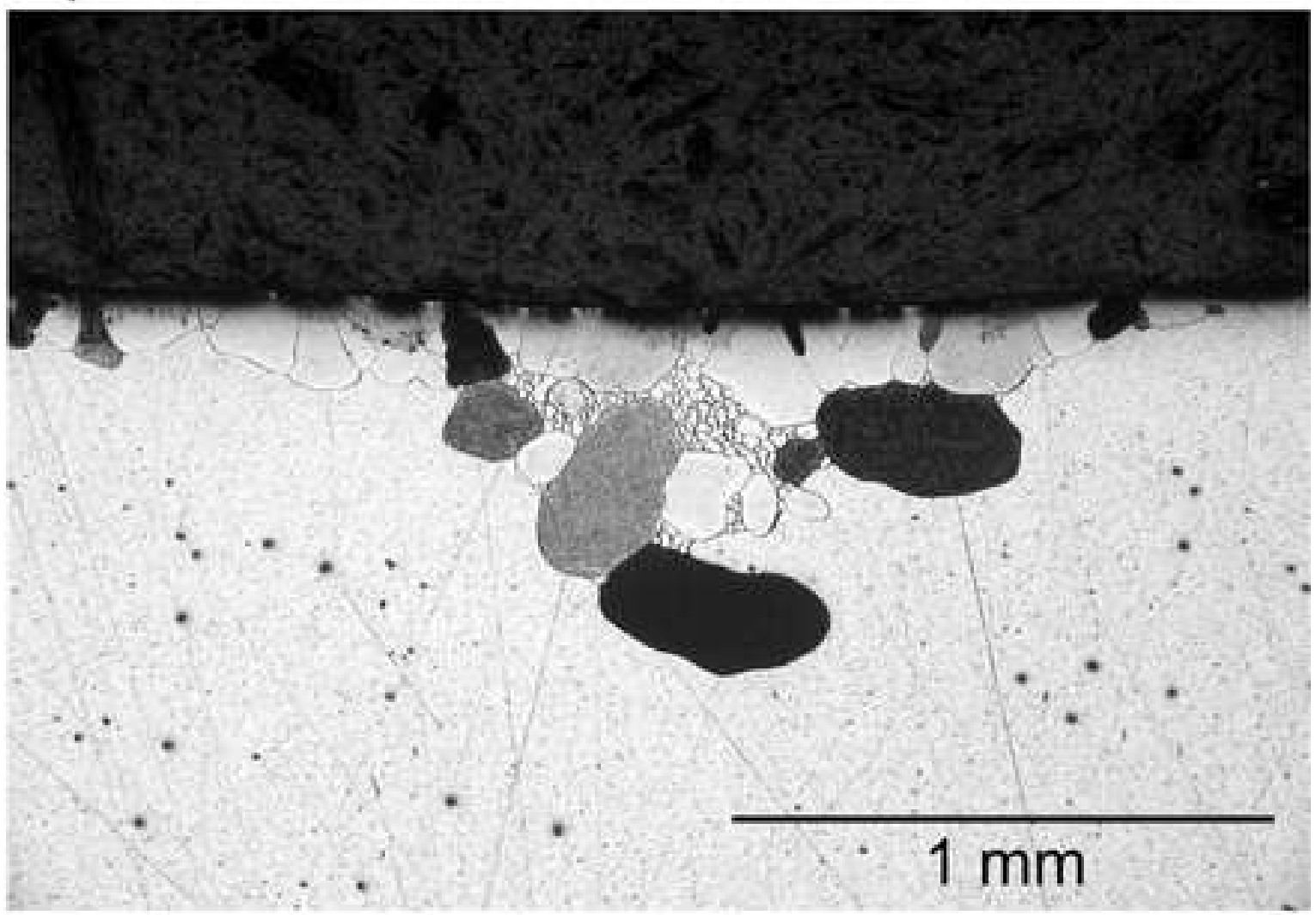

\section{b)}

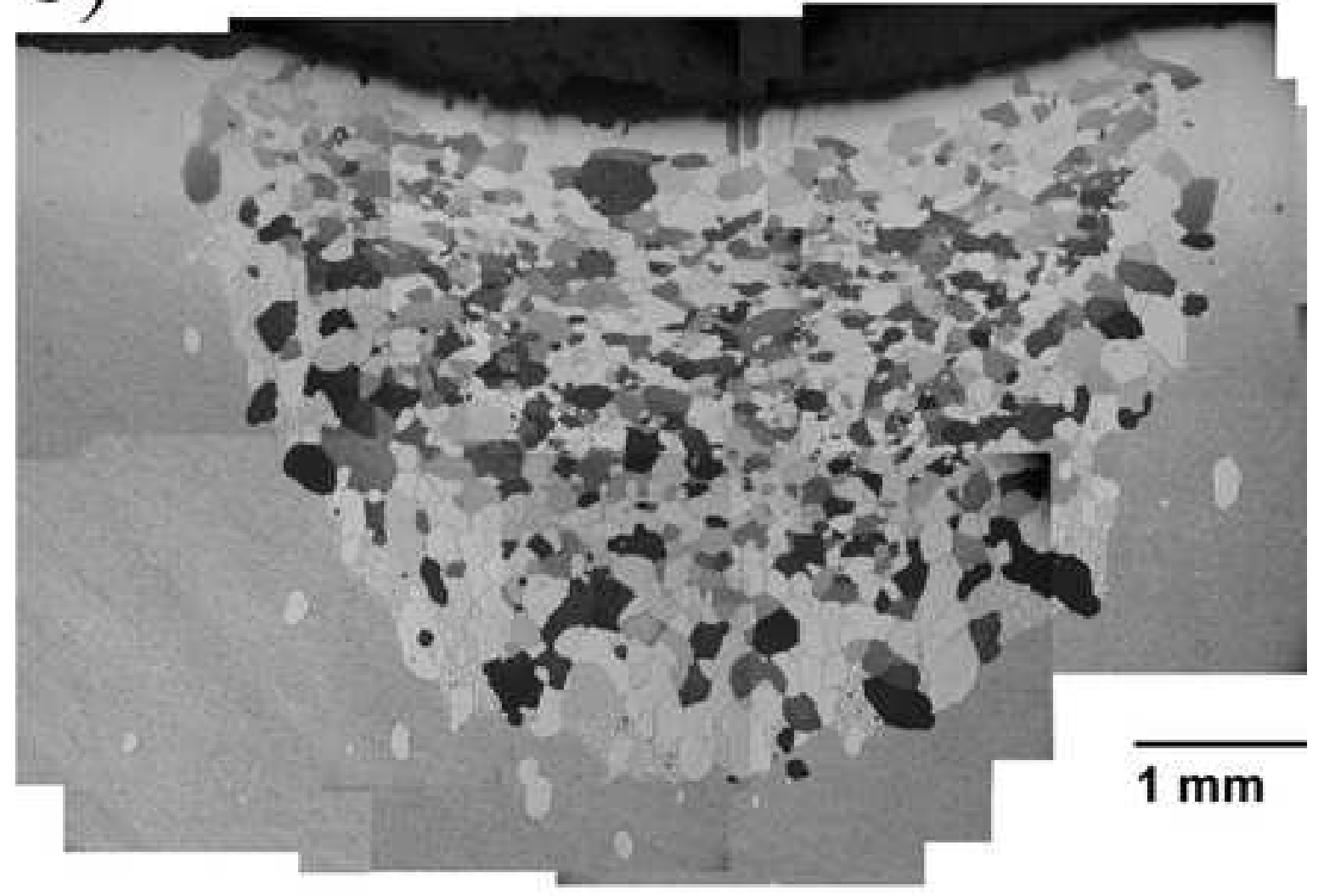


Figure 2
Click here to download high resolution image

a)
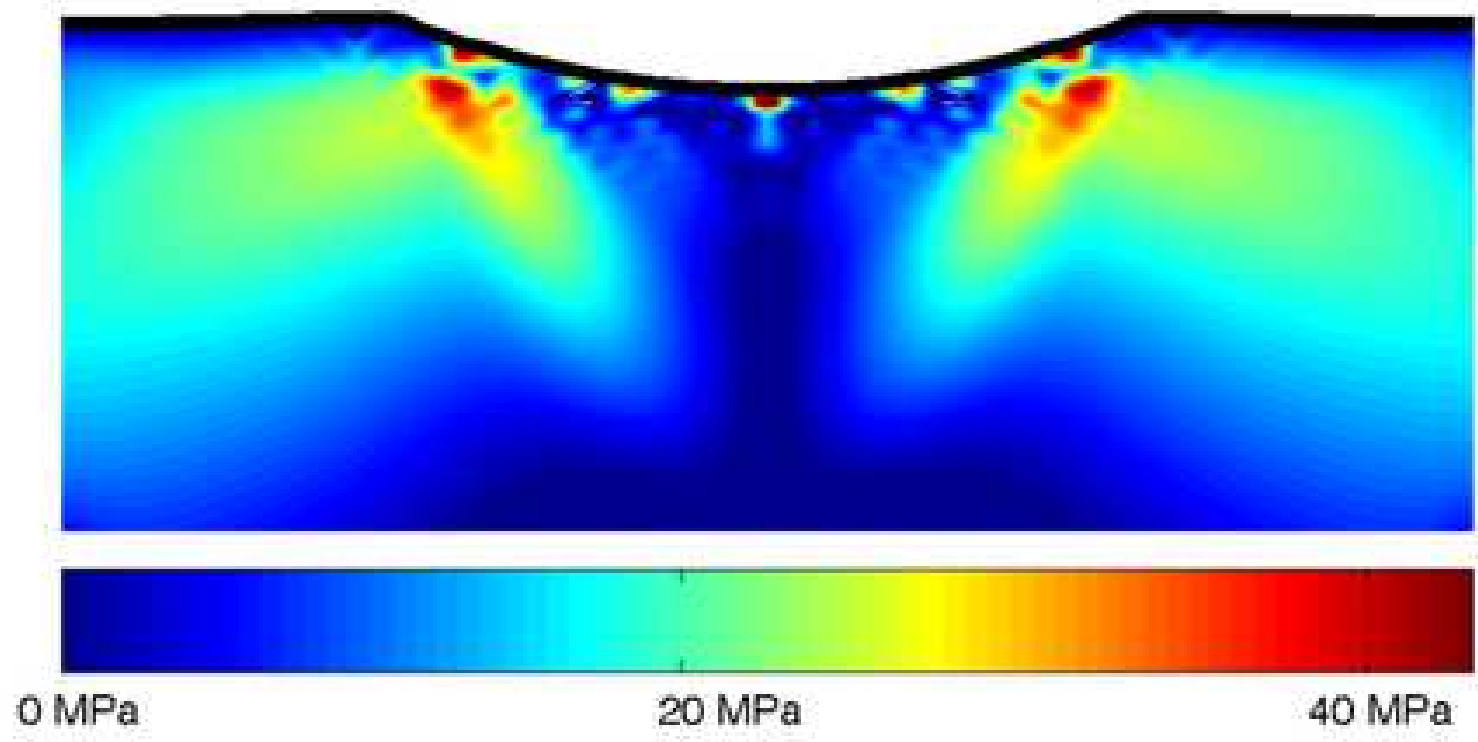

b)

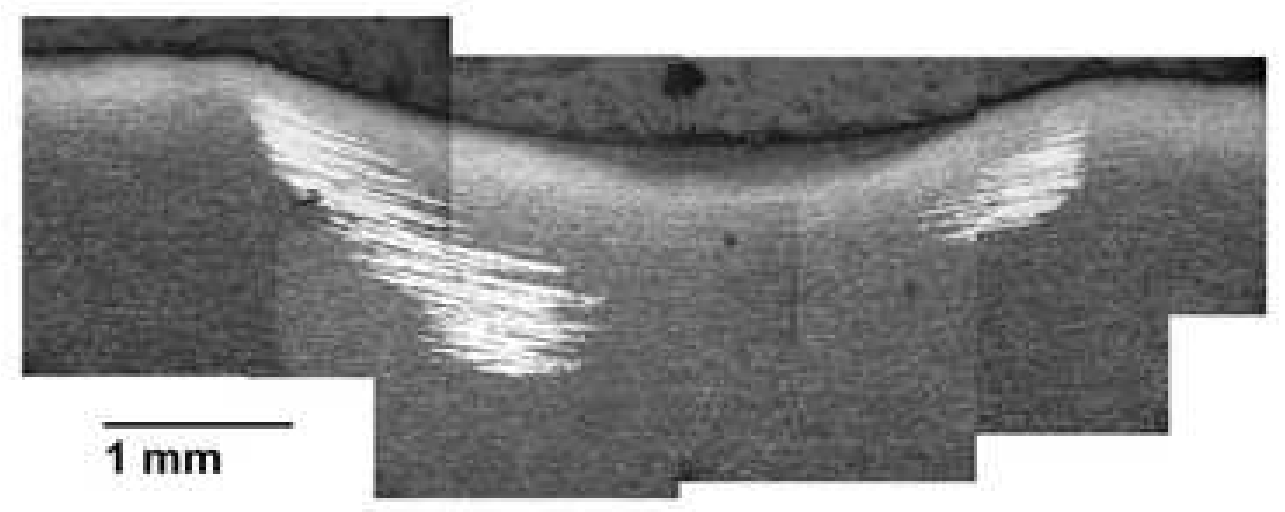

c)
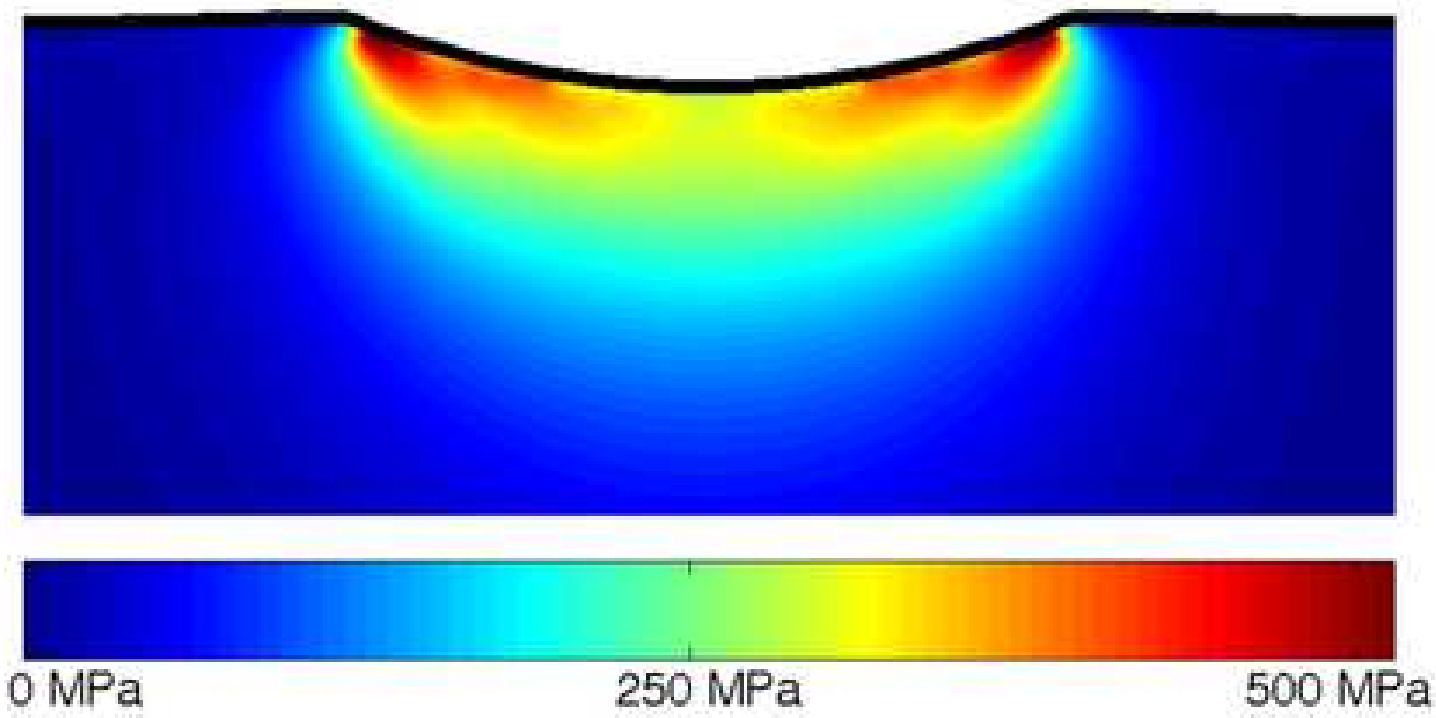
Click here to download high resolution image

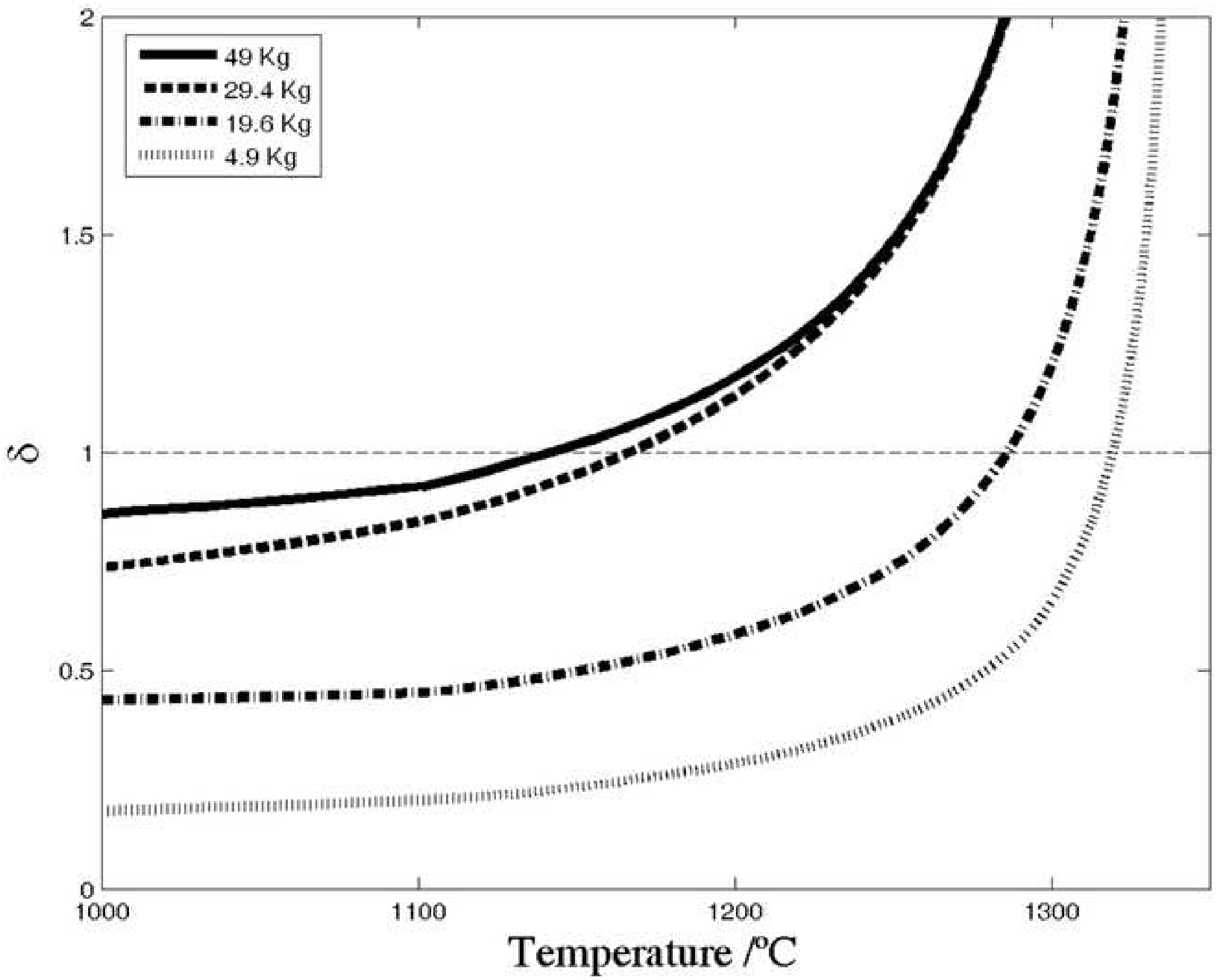


Click here to download high resolution image

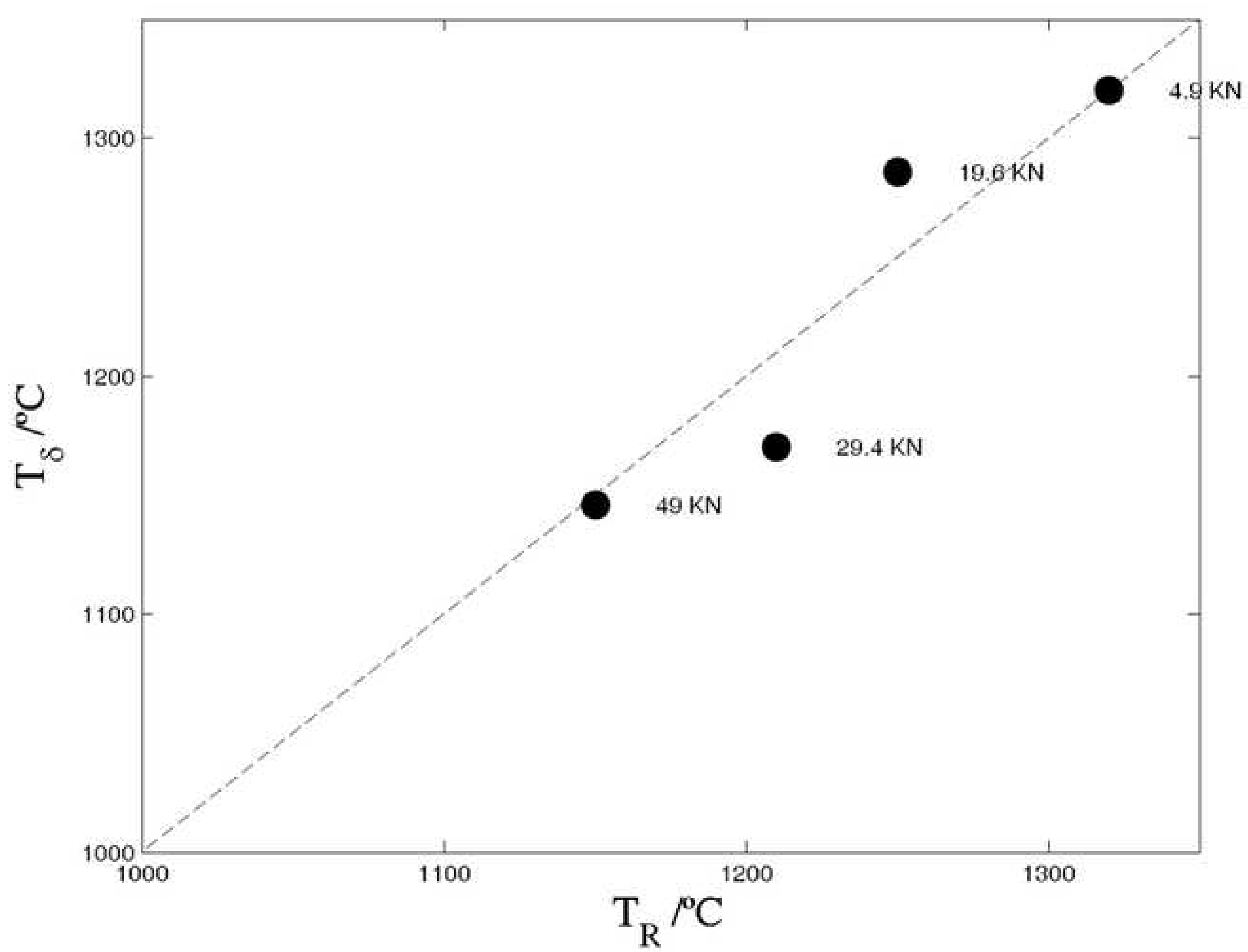

